\title{
Aftertreatment control and adaptation for automotive lean burn engines with HEGO sensors
}

\author{
Jing Sun ${ }^{1, * \dagger}$, Yong Wha $\mathrm{Kim}^{2,+}$ and Leyi Wang ${ }^{3, \S}$ \\ ${ }^{1}$ Naval Architecture and Marine Engineering Department, University of Michigan, 2600 Draper Road, Ann Arbor, \\ MI 48109-2145, U.S.A. \\ ${ }^{2}$ Powertrain Control Systems, Ford Research and Advanced Engineering, P. O. Box 2053, MD2036, SRL, 2101 Village \\ Road, Dearborn, MI 48121-2053, U.S.A. \\ ${ }^{3}$ Electrical and Computer Engineering Department, Wayne State University, Detroit, MI 48202, U.S.A.
}

\begin{abstract}
SUMMARY
Control of aftertreatment systems for lean burn technology engines represents a big challenge, due to the lack of on-board emission measurements and the sensitivity of the hardware components to ageing and sulphur poisoning. In this paper, we consider the control and adaptation of aftertreatment systems involving lean $\mathrm{NO}_{x}$ trap (LNT). A phenomenological LNT model is presented to facilitate the model-based control and adaptation. A control strategy based on the LNT model and HEGO (heated exhaust gas oxygen) sensor feedback is discussed. A linear parametric model, which is derived by exploiting the physical properties of the LNT is used for adaptation of trap capacity and feedgas $\mathrm{NO}_{x}$ emission models. The conditions under which parameter convergence will be achieved are derived for the proposed adaptive scheme. Simulation results for different scenarios are included to demonstrate the effectiveness of control and adaptation. Copyright (C) 2004 John Wiley \& Sons, Ltd.
\end{abstract}

KEY WORDS: adaptation; aftertreatment control; lean $\mathrm{NO}_{x}$ trap

\section{INTRODUCTION}

Lean burn technology for gasoline engines, including both direct injection stratified charge (DISC) and port fuel injection (PFI) engines, has drawn great attention during the past decade, largely due to its potential for improving fuel economy and reducing $\mathrm{CO}_{2}$ emissions. At part or low loads, a DISC or PFI lean burn engine can operate at high intake manifold pressure with an air-fuel mixture much leaner than the stoichiometric value. Consequently, combustion efficiency can be improved through reduced pumping losses and enhanced thermodynamic efficiency.

A challenge for lean burn technologies is that, under lean operating conditions, the conventional three-way catalyst (TWC) system is no longer effective in reducing $\mathrm{NO}_{x}$ pollutants.

\footnotetext{
*Correspondence to: J. Sun, 211 NAME, 2600 Draper Road, Ann Arbor, MI 48109-2145, U.S.A.

†E-mail: jingsun@umich.edu

‡-mail: ykim9@ford.com

§E-mail: lywang@ece.eng.wayne.edu

Copyright (C) 2004 John Wiley \& Sons, Ltd.
} 
A special TWC with $\mathrm{NO}_{x}$ trapping and conversion capabilities, also known as a lean $\mathrm{NO}_{x}$ trap (LNT) [1-4], has to be used downstream of the conventional TWC to meet the government emission standards. During lean operation, $\mathrm{NO}_{x}$ in the feedgas passing through the LNT is oxidized to $\mathrm{NO}_{2}$ and then stored as barium nitrate. The storage efficiency of the LNT decreases as the amount of stored $\mathrm{NO}_{x}$ increases. When its stored $\mathrm{NO}_{x}$ reaches a certain threshold, the trap must be purged by switching to rich operation for a short period of time to regenerate the storage sites and recover the efficiency $[2,5]$. When exposed to the rich exhaust environment, the nitrate becomes thermodynamically unstable and the stored $\mathrm{NO}_{x}$ is released from the $\mathrm{NO}_{x}$ storage sites. The released $\mathrm{NO}_{x}$ is then catalytically reduced by reductant such as $\mathrm{CO}, \mathrm{H}_{2}$ and $\mathrm{HC}$ in the feedgas.

To achieve the best tradeoff among competing requirements such as fuel economy, emissions, and driveability, the LNT control strategy must manage the purge starting time and duration, and at the same time provide a bumpless transition between the lean and purge modes. This turns out to be a very challenging task, for several reasons. First, the switches between lean and rich operation mandated by the LNT regeneration requirement have to be administrated bumplessly without causing any disturbance to the driver. This requires co-ordination of the purging operation with engine and transmission control. Second, the $\mathrm{NO}_{x}$ storage capacity of the LNT, one of the most critical parameters for its control strategies, varies dynamically. In particular, the trap is susceptible to sulphur poisoning [6]. Sulphur di-oxide, a by-product of the combustion process for engines fuelled by gasoline with sulphur content, will compete with the nitrates for active storage sites. As sulphates build up in the trap, the effective LNT trapping capacity is reduced. Worse yet, the adsorbed sulphates are not desorbed as easily as the nitrates and therefore cannot be as easily removed. Furthermore, the LNT has a narrow temperature window within which it has high trapping efficiency [2]. The effective capacity of the trap therefore will depend on the temperature, the age of the trap and other engine operating variables.

These challenges are further compounded by limited sensor information for LNT management. Due to cost constraints, on-line measurements for aftertreatment systems are still limited to air-to-fuel ratio (AFR) and temperature information, even for advanced technology engine systems. Most often, switching-type heated exhaust gas oxygen (HEGO) sensors are chosen over the linear universal exhaust gas oxygen (UEGO) sensors for AFR measurement, when both cost and robustness are taken into consideration. The signals that are most pertinent to the LNT operating status, such as $\mathrm{NO}_{x}$ at the engine exhaust or tailpipe locations, are typically not measured. Feedback controls using signals other than AFR and temperature have to rely on model prediction. Uncertainties and characteristic variations (due to ageing, sulphur poisoning, component-to-component variation, etc.) have to be addressed through real-time identification and on-line adaptation.

In Reference [5], a control strategy is presented which adapts to the uncertainties in the LNT $\mathrm{NO}_{x}$ storage capacity and in the amount of available reductant $(\mathrm{HC}$ and $\mathrm{CO}$ ) during the purge phase. The scheme is based on an early LNT model developed by Wang et al. [4]. The model structure of Reference [4] and the uncertainties addressed in Reference [5] led to a non-linear parametric model for which most standard adaptation algorithms cannot be applied. Persistent excitation, a condition normally required for parameter convergence, was shown in Reference [5] as a requirement for changing purge threshold. An on-line recursive algorithm was developed to ease the computational requirements of the identification. Nevertheless, the computational efforts required to handle the non-linearity in the parametric model put constraints on the 
implementation of Reference [5] for on-board applications where the computational power is very limited and expensive.

More recently, advances in LNT materials have motivated the development of new trap models for control strategy design. The LNT model in Reference [7] relates the key dynamics of the purge operation to AFR, thereby relaxing the dependency of the model on the accuracy of the reductant estimations (for $\mathrm{HC}$ and $\mathrm{CO}$ ). This new feature suggested that we focus on other sources of uncertainties in the LNT control problem, namely the variations in the incoming $\mathrm{NO}_{x}$ flow and the LNT $\mathrm{NO}_{x}$ capacity.

In this paper, we exploit the new model [7] to investigate feasible methodologies for LNT purge strategies by combining sensor information processing, real-time identification, and online adaptation. As in Reference [5], real world constraints dictated our sensor configuration: only HEGO and temperature sensors are assumed available. A control strategy that manages the LNT purge cycle will be investigated. Both the model-based prediction and HEGO sensor information are used for feedback and on-line adaptation to minimize $\mathrm{HC}$ and $\mathrm{CO}$ emissions as well as the fuel economy penalty incurred by the LNT regeneration. By incorporating the physical properties of the system, and properly choosing the structure for the LNT model and parametrization for the uncertainties, a linear parametric model is developed for on-line adaptation, therefore mitigating the difficulties in implementing the adaptive algorithm proposed in Reference [5] due to the non-linear parametric model. Furthermore, a persistent excitation condition will be established for parameter convergence for the proposed adaptation scheme.

The paper is organized as follows. Section 2 presents a control-oriented LNT model that captures the dynamics of the $\mathrm{NO}_{x}$ and oxygen storage and purge mechanism. Based on our understanding of the LNT chemical reactions and our observations from the experimental data, a dynamic $\mathrm{NO}_{x}$ model structure is introduced. A control strategy that combines model-based prediction and HEGO-sensor based feedback will be discussed in detail in Section 3. A modelbased adaptation scheme for the LNT purge strategy is developed in Section 4. A recursive adaptation algorithm based on HEGO switch timing is introduced to accommodate uncertainties in feedgas $\mathrm{NO}_{x}$ flow characteristics and $\mathrm{LNT} \mathrm{NO}_{x}$ storage capacity. Conditions under which parameter convergence occurs will be introduced. Simulation results for the adaptive scheme introduced in this paper are included in Section 5. Finally, a summary of the research observations and potential future research directions will be briefly explored in Section 6.

\section{CHARACTERISTICS AND MODELS OF THE LNT AND HEGO SENSOR}

A typical aftertreatment system for a lean burn engine with a commonly used sensor configuration is shown in Figure 1. It consists of a conventional TWC (usually in a closely coupled location with the engine for optimal cold start performance), an underbody special TWC or LNT, a switching-type HEGO sensor downstream of the LNT, a temperature sensor upstream of the LNT (marked as T/C in Figure 1), and possibly a UEGO sensor upstream of the TWC for AFR control. Additional sensors, such as a HEGO or UEGO between the LNT and TWC, or a $\mathrm{NO}_{x}$ sensor downstream of the LNT, can add valuable information for the control and diagnostics of the system, but are often prohibited due to cost constraints. 


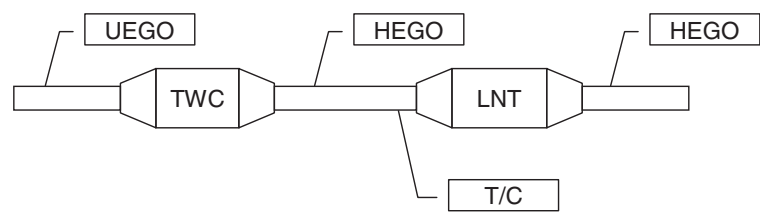

Figure 1. Typical aftertreatment system configuration for lean burn engine.

To develop an effective aftertreatment strategy for LNT management, one has to consider many operational and environmental variables and parameters, including:

- Feedgas properties. These include the AFR, temperature, $\mathrm{NO}_{x}$ concentration, reductant (i.e. $\mathrm{CO}, \mathrm{H}_{2}, \mathrm{HC}$ ) concentrations, and their flow rates. Those variables are the inputs to the aftertreatment system. It should be noted that there is no direct actuator that is exclusively reserved for the aftertreatment control. The control functions are accomplished by the engine through the feedgas variables.

- The internal states of the LNT. These include the stored $\mathrm{NO}_{x}$ and oxygen in the LNT. Their dynamics are affected by the feedgas which are the inputs to the LNT, and the LNT parameters.

- Sensor information. The control system relies critically on the information from the HEGO and temperature sensors for its operation.

Understanding the dynamic and causal relations among the inputs, internal states, system parameters, and sensor information will be of fundamental importance in LNT strategy development. The rest of this section is devoted to the discussion of system characteristics and the models representing them.

\subsection{Key chemical processes of an LNT operation}

For self-containment, we will briefly describe the key chemical reactions that dictate the behaviour of the LNT. Depending on the exhaust gas condition, different dominant chemical reactions will take place within the LNT. A pictorial description of the storage and purge processes is shown in Figure 2.

Storage phase: When the exhaust gas is leaner than stoichiometric, $\mathrm{NO}_{x}$ is oxidized to $\mathrm{NO}_{2}$ in the gas phase (Equation (1)) and the resulting $\mathrm{NO}_{2}$ is then adsorbed on storage sites as barium nitrate (Equation (2)). This process is termed as $\mathrm{NO}_{x}$ storage.

$$
\begin{gathered}
\mathrm{NO}+\frac{1}{2} \mathrm{O}_{2} \leftrightarrow \mathrm{NO}_{2} \\
\frac{1}{2} \mathrm{BaCO}_{3}+\mathrm{NO}_{2}+\frac{1}{4} \mathrm{O}_{2} \leftrightarrow \frac{1}{2} \mathrm{Ba}\left(\mathrm{NO}_{3}\right)_{2}+\frac{1}{2} \mathrm{CO}_{2}
\end{gathered}
$$

Purge/regeneration phase: As the $\mathrm{NO}_{x}$ stored in the LNT increases, the storage efficiency drops and the trap needs to be purged to regenerate its capacity once the stored $\mathrm{NO}_{x}$ reaches a certain level. The purge can be accomplished by providing a rich exhaust environment to the trap. The nitrate, $\mathrm{Ba}\left(\mathrm{NO}_{3}\right)_{2}$ for the LNT under consideration, becomes thermodynamically unstable under stoichiometric or rich exhaust conditions and releases $\mathrm{NO}_{2}$ and $\mathrm{BaO}$ (Equation (3)). $\mathrm{BaO}$ then becomes $\mathrm{BaCO}_{3}$, thereby regenerating the storage sites, as shown in 

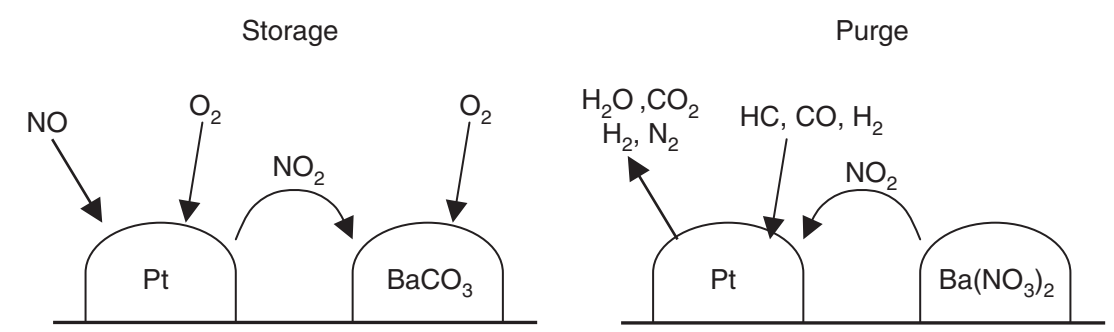

Figure 2. Key chemical reactions for storage and purge process in lean $\mathrm{NO}_{x}$ trap.

Equation (4). This step is referred to as $\mathrm{NO}_{x}$ release and trap regeneration.

$$
\begin{gathered}
\mathrm{Ba}\left(\mathrm{NO}_{3}\right)_{2} \leftrightarrow \mathrm{BaO}+2 \mathrm{NO}_{2}+\frac{1}{2} \mathrm{O}_{2} \\
\mathrm{BaO}+\mathrm{CO}_{2} \rightarrow \mathrm{BaCO}_{3}
\end{gathered}
$$

The released $\mathrm{NO}_{2}$ is converted to $\mathrm{N}_{2}$ by the reductant, such as $\mathrm{CO}, \mathrm{H}_{2}$ and $\mathrm{HC}$, over the precious metal sites (platinum for example). The reactions involved are summarized in (5)-(7).

$$
\begin{gathered}
\mathrm{NO}_{2} \rightarrow \mathrm{NO}+\frac{1}{2} \mathrm{O}_{2} \\
\mathrm{CO}+\mathrm{NO} \rightarrow \mathrm{CO}_{2}+\frac{1}{2} \mathrm{~N}_{2} \\
\mathrm{C}_{n_{\mathrm{c}}} H_{n_{h}}+\left(2 n_{\mathrm{c}}+\frac{n_{h}}{2}\right) \mathrm{NO} \rightarrow n_{\mathrm{c}} \mathrm{CO}_{2}+\frac{n_{h}}{2} \mathrm{H}_{2} \mathrm{O}+\left(n_{\mathrm{c}}+\frac{n_{h}}{2}\right) \frac{9}{2} \mathrm{~N}_{2}
\end{gathered}
$$

This process, consisting of $\mathrm{NO}_{x}$ release (3), trap regeneration (4) and $\mathrm{NO}_{x}$ conversion (5)-(7), is referred to as LNT purge.

\subsection{Control-oriented LNT models}

A control-oriented model which describes the storage and purge process at the phenomenological level is described below. The storage model structure is mainly from a prior work [4]. The purge model of Reference [4] is further extended to accommodate new observations gained from our experiments and data analysis.

$N O_{x}$ storage: By mass conservation, assuming low and negligible $\mathrm{NO}_{x}$ conversion efficiency during lean operation, the $\mathrm{NO}_{x}$ accumulated in the LNT during the storage phase is

$$
m_{\mathrm{NO}_{x}, \text { stored }}=m_{\mathrm{NO}_{x}, \text { in }}-m_{\mathrm{NO}_{x}, \mathrm{tp}}
$$

where $m_{\mathrm{NO}_{x}}$,stored is the stored $\mathrm{NO}_{x}[\mathrm{~g}], m_{\mathrm{NO}_{x}}$,in is $\mathrm{NO}_{x}$ entering the LNT [g] and $m_{\mathrm{NO}_{x}, \text { tp }}$ is $\mathrm{NO}_{x}$ leaving the LNT $[\mathrm{g}]$. The storage instantaneous efficiency, $\eta_{\mathrm{s}}$, defined as

$$
\eta_{\mathrm{s}}=\frac{\dot{m}_{\mathrm{NO}_{x}, \text { in }}-\dot{m}_{\mathrm{NO}_{x}, \mathrm{tp}}}{\dot{m}_{\mathrm{NO}_{x}, \text { in }}}
$$

provides a measurement of the effectiveness of the trap in treating $\mathrm{NO}_{x}$ in the storage phase. Combining (8) and (9), we have

$$
\dot{m}_{\mathrm{NO}_{x}, \text { stored }}=\eta_{\mathrm{s}} \dot{m}_{\mathrm{NO}_{x}, \text { in }}
$$


On the other hand, it is convenient to express the stored $\mathrm{NO}_{x}$ in terms of the LNT storage capacity $C_{\mathrm{LNT}}[\mathrm{g}]$ as

$$
m_{\mathrm{NO}_{x}, \text { stored }}=C_{\mathrm{LNT}} x
$$

where $x$ is the fraction of utilized LNT capacity (or the fraction of occupied storage sites). Then, we have

$$
\dot{m}_{\mathrm{NO}_{x}, \text { stored }}=\frac{\mathrm{d} C_{\mathrm{LNT}}}{\mathrm{d} t} x+C_{\mathrm{LNT}} \frac{\mathrm{d} x}{\mathrm{~d} t}
$$

Equations (10) and (12), when combined, describe the storage dynamics given by

$$
\dot{x}=-\frac{1}{C_{\mathrm{LNT}}} \frac{\mathrm{d} C_{\mathrm{LNT}}}{\mathrm{d} t} x+\frac{1}{C_{\mathrm{LNT}}} \eta_{\mathrm{s}} \dot{m}_{\mathrm{NO}_{x}, \text { in }}
$$

The storage capacity $C_{\mathrm{LNT}}$ for a typical trap is shown in Figure 3(a). It can be modelled as a Gaussian function of the temperature $T$ that has centre $T_{\mathrm{m}}\left[{ }^{\circ} \mathrm{C}\right]$, span $T_{\mathrm{s}}\left[{ }^{\circ} \mathrm{C}\right]$, and peak capacity $C_{\mathrm{m}}[\mathrm{g}]:$

$$
C_{\mathrm{LNT}}=C_{\mathrm{m}} \exp \left[-\left(\frac{T-T_{\mathrm{m}}}{T_{\mathrm{s}}}\right)^{2}\right]
$$

For a given trap, parameters $T_{\mathrm{m}}, T_{\mathrm{s}}, C_{\mathrm{m}}$ can be identified from experimental data.

The instantaneous storage efficiency $\eta_{\mathrm{s}}$, on the other hand, changes as a function of the LNT state $x$ and the trap temperature, as shown in Figure 3(b). In this work, the storage efficiency is described by the function

$$
\eta_{\mathrm{s}}=\frac{\mathrm{e}^{-\alpha x}-\mathrm{e}^{-\alpha}}{1-\mathrm{e}^{-\alpha}}
$$

where $\alpha$ is a parameter that incorporates the effects of the trap temperature on storage efficiency.

$N O_{x}$ purge: During the purge phase, the stored $\mathrm{NO}_{x}$ is released from the storage sites. By mass conservation we have

$$
\dot{m}_{\mathrm{NO}_{x}, \text { stored }}=-\dot{m}_{\mathrm{NO}_{x}, \mathrm{r}}
$$

where $\dot{m}_{\mathrm{NO}_{x}, \mathrm{r}}$ is the $\mathrm{NO}_{x}$ release rate. Equations (12) and (16) imply that when $\lambda_{\text {in }} \leqslant 1$,

$$
\frac{\mathrm{d} x}{\mathrm{~d} t}=-\frac{1}{C_{\mathrm{LNT}}} \frac{\mathrm{d} C_{\mathrm{LNT}}}{\mathrm{d} t} x-\frac{\dot{m}_{\mathrm{NO}_{x}, \mathrm{r}}}{C_{\mathrm{LNT}}}
$$

The release rate, $\dot{m}_{\mathrm{NO}_{x}, \mathrm{r}}$, depends on how much $\mathrm{NO}_{x}$ is stored in the trap and the trap capacity, as shown in Figure 4(a) where three different traps with identical formulation but different sizes are plotted. However, the correlation of the release rate with the capacity is linear, as the data show. By introducing the normalized release rate, i.e.

$$
k_{\mathrm{r}} \triangleq \frac{\dot{m}_{\mathrm{NO}_{x}, \mathrm{r}}}{C_{\mathrm{LNT}}}
$$

we can see that different plots of Figure 4(a) corresponding to traps with different capacities all collapse into one single curve in Figure 4(b).

The normalized release rate depends on several variables, including the AFR (which determines the level of reductant in the exhaust stream), the flow rate or the space-velocity, 


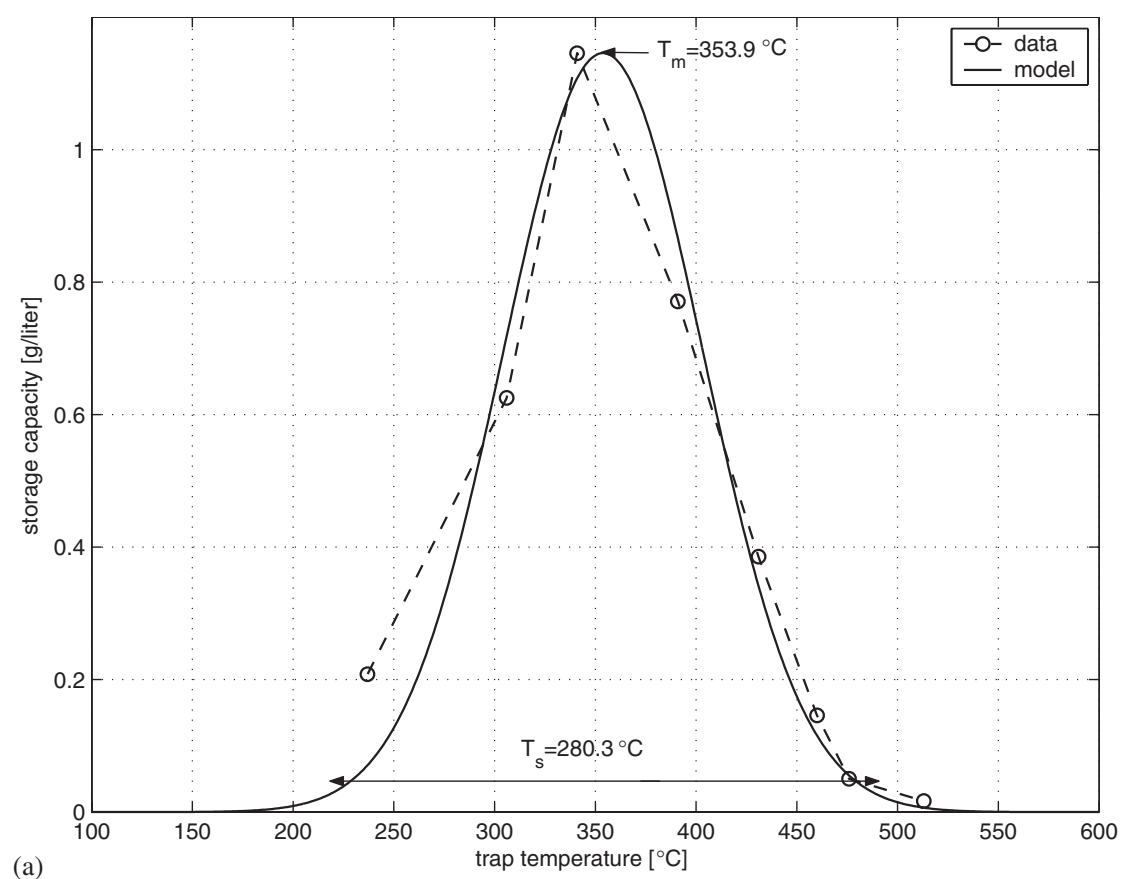

(a)

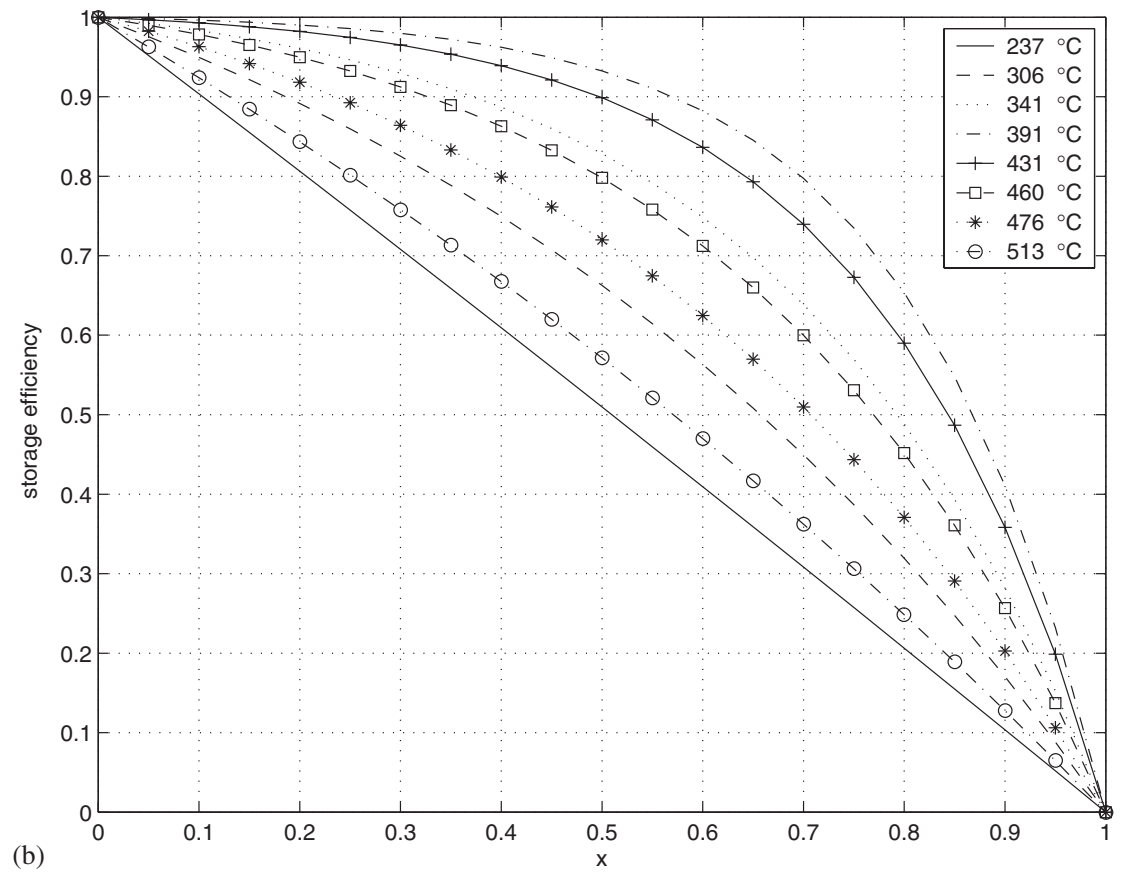

Figure 3. Lean $\mathrm{NO}_{x}$ trap storage model parameters. (a) Storage capacity, (b) storage efficiency. 


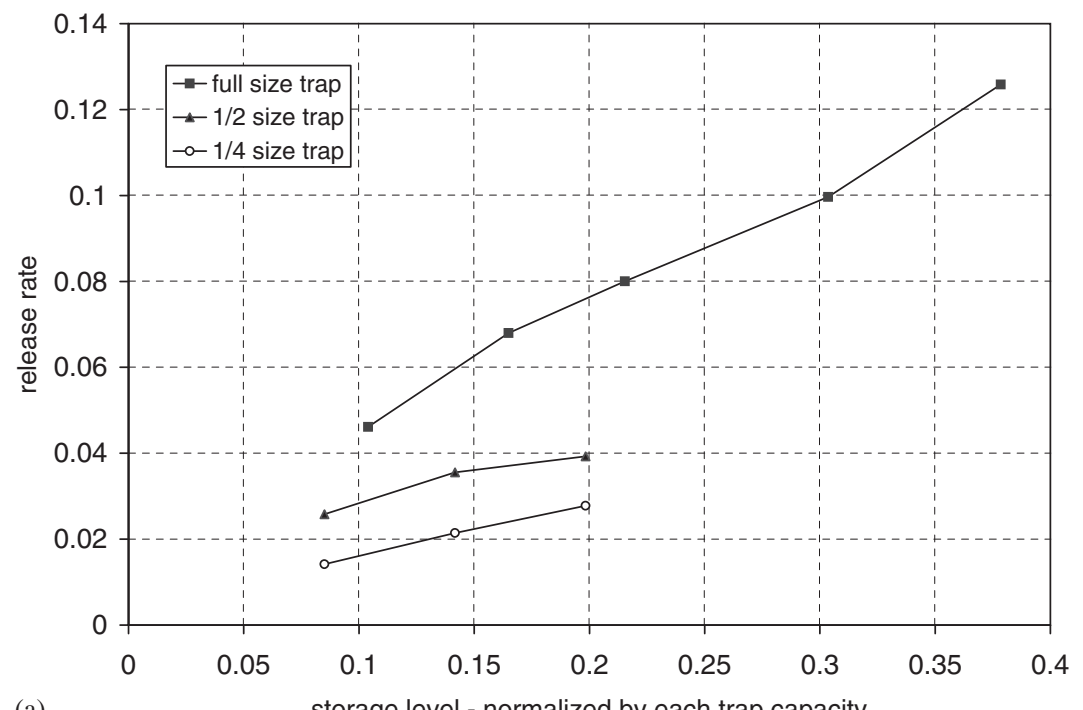

(a)

storage level - normalized by each trap capacity

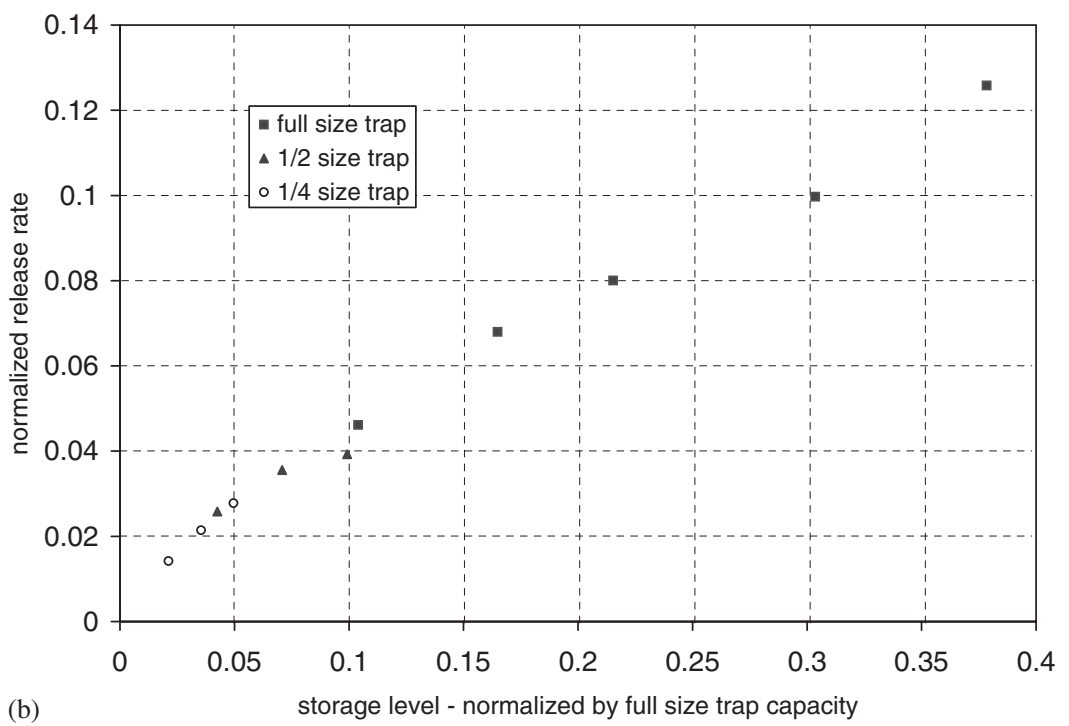

Figure 4. Release rate for traps with various capacity.

temperature, etc. For the work described in this paper, the normalized release rate is identified by the following function:

$$
k_{\mathrm{r}}=\frac{1-\mathrm{e}^{\beta x}}{1-\mathrm{e}^{x}}\left(1-x_{\text {oxy }}\right) f_{\mathrm{r}}\left(\lambda_{\text {in }}, W_{\mathrm{a}}, T\right)
$$

where $x_{\text {oxy }}$ is the oxygen storage level in the LNT, $\lambda_{\text {in }}$ is the relative AFR at the LNT entrance, $W_{\mathrm{a}}$ is the mass air flow rate, and $\beta$ is a parameter depending on the catalyst physical properties, such as formulation, geometry, etc. The second term on right-hand side $\left(1-x_{\mathrm{oxy}}\right)$ captures the interactions between $\mathrm{NO}_{x}$ and oxygen storage mechanisms. It should be noted that $x_{\mathrm{oxy}}$ is also a 

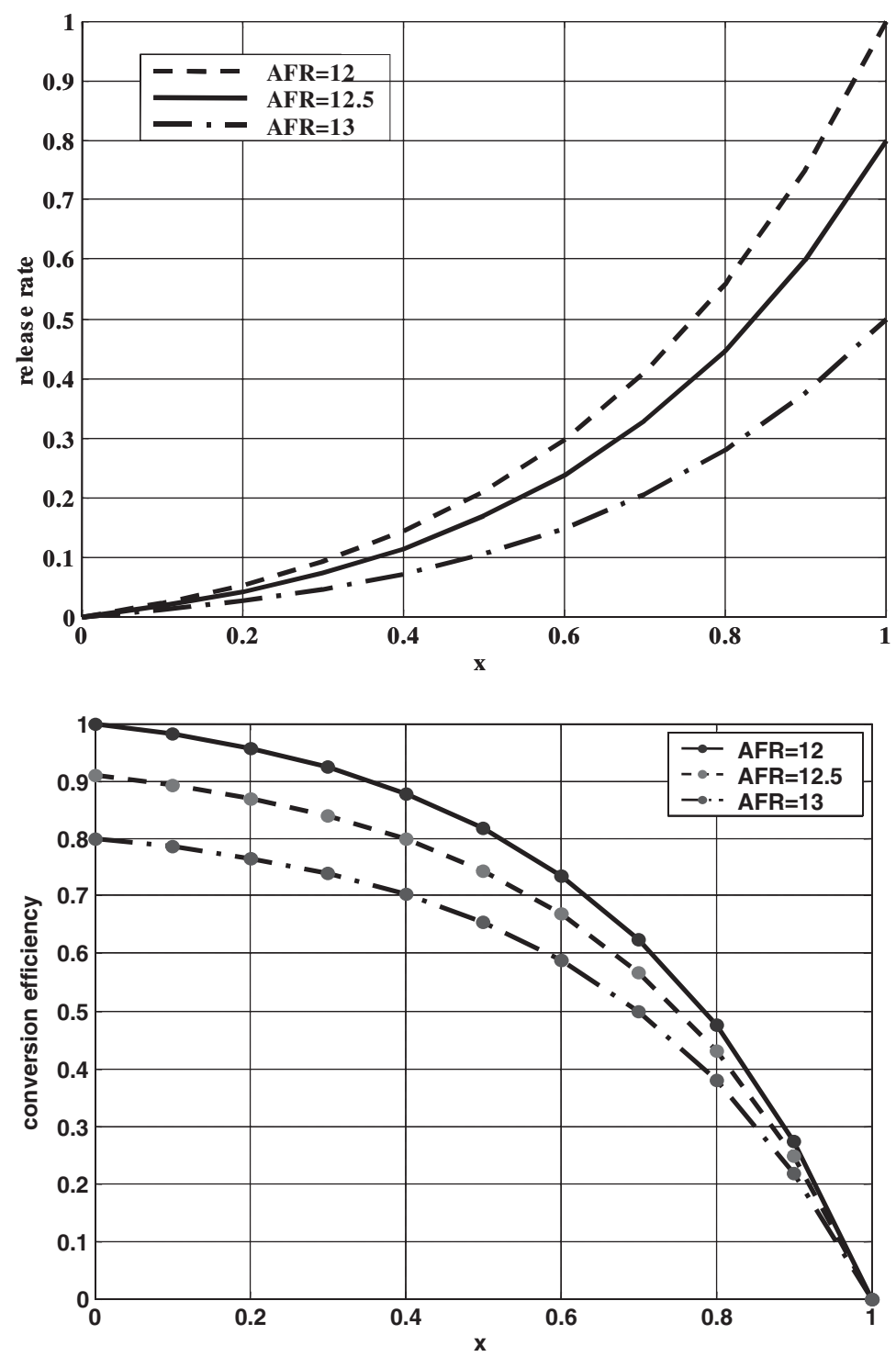

Figure 5. Lean $\mathrm{NO}_{x}$ trap purge model parameters. (a) Release rates, (b) conversion efficiencies.

dynamic variable, which will be discussed shortly. The function $f_{\mathrm{r}}\left(\lambda_{\text {in }}, W_{\mathrm{a}}, T\right)$ takes into account the effect of AFR at the LNT entrance, space-velocity and temperature. Figure 5(a) illustrates the release rate as a function of storage level and purge AFR with $x_{\text {oxy }}=0$.

The last step in trap regeneration is to convert the released $\mathrm{NO}_{x}$ into non-pollutant species, primarily by the reductant, such as $\mathrm{HC}$ and $\mathrm{CO}$. The efficiency of this process, defined as

$$
\eta_{\mathrm{c}}=\frac{\dot{m}_{\mathrm{NO}_{x}, \mathrm{r}}-\dot{m}_{\mathrm{NO}_{x}, \mathrm{tp}}}{\dot{m}_{\mathrm{NO}_{x}, \mathrm{r}}}
$$


also depends on AFR, flowrate and temperature. It is modelled by Equation (20) and depicted in Figure 5(b):

$$
\eta_{\mathrm{c}}=\frac{\mathrm{e}^{\gamma x}-\mathrm{e}^{\gamma}}{1-\mathrm{e}^{\gamma}} f_{\mathrm{c}}\left(\lambda_{\mathrm{in}}, W_{\mathrm{a}}, T\right)
$$

where $\gamma$ is a parameter and $f_{\mathrm{c}}\left(\lambda_{\mathrm{in}}, W_{\mathrm{a}}, T\right)$ accounts for the effects of the AFR, temperature and mass flow rate (or space-velocity) of the exhaust gas.

By using the indicate function $I_{\{A\}}\left(I_{\{A\}}=1\right.$, if $A$ is satisfied; $I_{\{A\}}=0$, otherwise) the dynamics of the LNT can be described by

$$
\frac{\mathrm{d} x}{\mathrm{~d} t}=-\frac{1}{C_{\mathrm{LNT}}} \frac{\mathrm{d} C_{\mathrm{LNT}}}{\mathrm{d} t} x+I_{\left\{\lambda_{\mathrm{in}}>1\right\}} \eta_{\mathrm{s}} \frac{\dot{m}_{\mathrm{NO}_{x}, \mathrm{in}}}{C_{\mathrm{LNT}}}-I_{\left\{\lambda_{\mathrm{in}} \leqslant 1\right\}} \frac{\dot{m}_{\mathrm{NO}_{x}, \mathrm{r}}}{C_{\mathrm{LNT}}}
$$

for both storage and purge operation. The $\mathrm{NO}_{x}$ flow rate leaving the $\mathrm{LNT}, \dot{m}_{\mathrm{NO}_{x}}$,tp , is

$$
\dot{m}_{\mathrm{NO}_{x}, \mathrm{tp}}=I_{\left\{\lambda_{\text {in }}>1\right\}}\left(1-\eta_{\mathrm{s}}\right) \dot{m}_{\mathrm{NO}_{x}, \text { in }}+I_{\left\{\lambda_{\text {in }} \leqslant 1\right\}}\left(1-\eta_{\mathrm{c}}\right) \dot{m}_{\mathrm{NO}_{x}, \mathrm{r}}
$$

Oxygen storage and purge: The oxygen storage model used here is adopted from the work described in Reference [8]. The dynamics of oxygen storage are described, in either lean (storage) or rich (release) operations, as

$$
\frac{\mathrm{d} x_{\text {oxy }}}{\mathrm{d} t}=\left\{\begin{array}{lll}
\frac{0.21}{C_{\text {oxy }}} \alpha_{\mathrm{L}} \rho_{\mathrm{L}}\left(x_{\text {oxy }}\right) W_{\mathrm{a}}\left(1-\frac{1}{\lambda_{\text {in }}}\right), & \lambda_{\text {in }} \geqslant 1, \\
\frac{0.21}{C_{\text {oxy }}} \alpha_{\mathrm{R}} \rho_{\mathrm{R}}\left(x_{\text {oxy }}\right) W_{\mathrm{a}}\left(1-\frac{1}{\lambda_{\text {in }}}\right), & \lambda_{\text {in }}<1, & 0 \leqslant x_{\text {oxy }}<1
\end{array}\right.
$$

where $x_{\text {oxy }}=m_{\text {oxy }} / C_{\text {oxy }}$ ( $m_{\text {oxy }}$ being the total oxygen stored $)$ is the relative amount of stored oxygen with respect to the available oxygen storage capacity $C_{\text {oxy }}$. Here, $\alpha_{\mathrm{L}}$ and $\alpha_{\mathrm{R}}$ are constants and $\rho_{\mathrm{L}}\left(x_{\mathrm{oxy}}\right)$ and $\rho_{\mathrm{R}}\left(x_{\mathrm{oxy}}\right)$ are non-linear functions indicating the relative storage and release rates, respectively, as shown in Figure 6.

The tailpipe AFR, affected by the oxygen storage dynamics, is determined by

$$
\lambda_{\text {tp }}= \begin{cases}\lambda_{\text {in }}-\alpha_{\mathrm{L}} \rho_{\mathrm{L}}\left(x_{\text {oxy }}\right)\left(\lambda_{\text {in }}-1\right) & \text { if } \lambda_{\text {in }}>1 \\ \lambda_{\text {in }}-\alpha_{\mathrm{R}} \rho_{\mathrm{R}}\left(x_{\text {oxy }}\right)\left(\lambda_{\text {in }}-1\right) & \text { if } \lambda_{\text {in }}<1\end{cases}
$$

\subsection{HEGO sensor characteristics}

The control and adaptation algorithms introduced in this paper rely critically on characterizations of HEGO sensors. Depending on the application, two different HEGO sensor characterizations are available to correlate the output voltage of a HEGO sensor to the properties of the mixture $[9,10]$. One expresses the voltage as a function of the AFR, the other relates the voltage output to the more fundamental properties of the exhaust gas through the redox number, i.e. the balance between the oxidants and reductant $[9,10]$. In this application, we will be using the HEGO characteristic from the AFR perspective.

For a given temperature, HEGO voltage $v$ is a function of the relative AFR $\lambda[9,10]$. A typical form of the function is characterized by high-voltage flat section when $\lambda \leqslant \lambda_{\mathrm{f}}$; a continuous one-to-one function when $\lambda_{\mathrm{f}}<\lambda \leqslant \lambda_{\mathrm{s}}-\varepsilon$; and a sharp drop to a low-voltage $v_{\mathrm{s}}$ between 


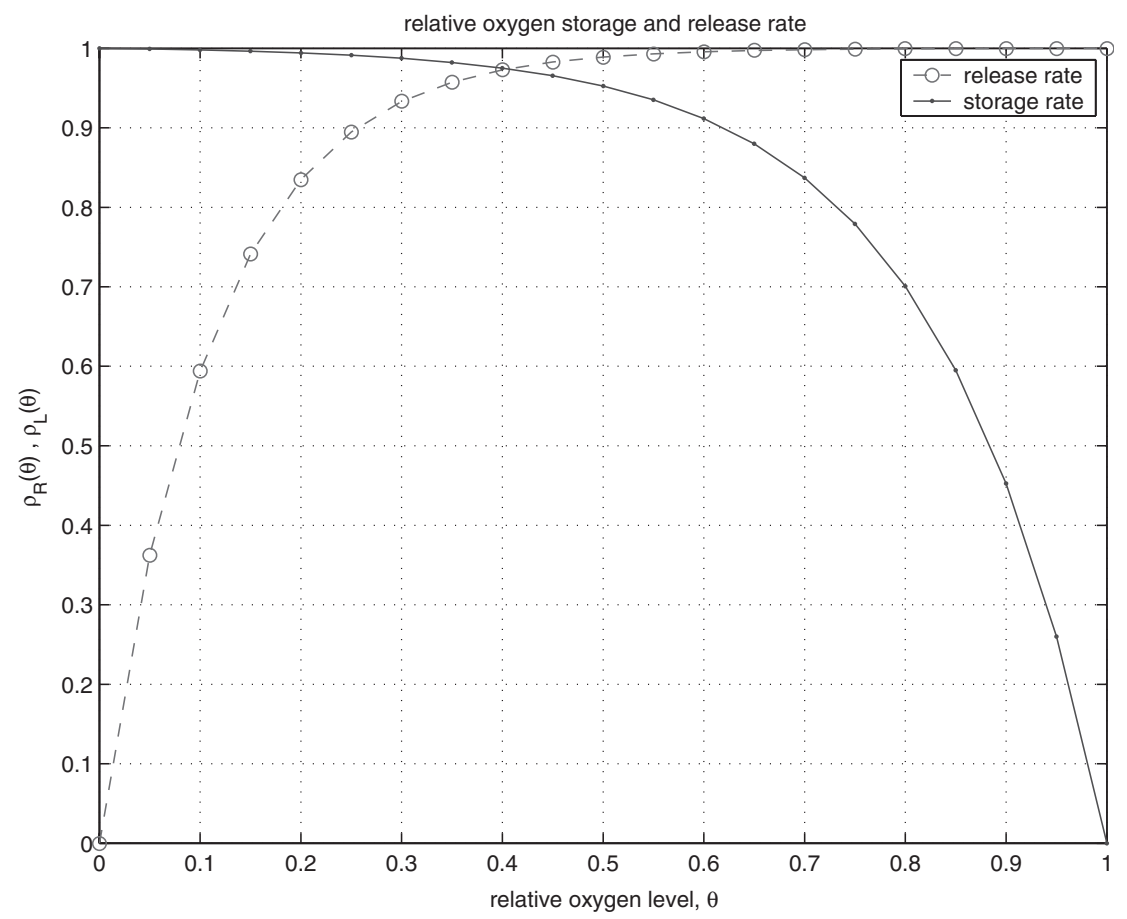

Figure 6. Oxygen storage and release rate from oxygen storage model.

$\lambda \geqslant \lambda_{\mathrm{s}}-\varepsilon$ and $\lambda \leqslant \lambda_{\mathrm{s}}+\varepsilon$ :

$$
v= \begin{cases}v_{\mathrm{f}}, & \lambda \leqslant \lambda_{\mathrm{f}}, \\ g(\lambda), & \lambda_{\mathrm{f}}<\lambda \leqslant \lambda_{\mathrm{s}}-\varepsilon, \\ g_{1}(\lambda), & \lambda_{\mathrm{s}}-\varepsilon \leqslant \lambda<\lambda_{\mathrm{s}}+\varepsilon, \\ v_{\mathrm{s}}, & \lambda \geqslant \lambda_{\mathrm{s}}+\varepsilon\end{cases}
$$

where $\varepsilon$ is a small value describing the narrow window of voltage drop. Within this window, the voltage drops rapidly and $\lambda \approx \lambda_{\mathrm{s}}$. As a typical example, an interpolated HEGO voltage curve [11] is depicted in Figure 7. This HEGO sensor has $\lambda_{\mathrm{f}}=0.96, \lambda_{\mathrm{s}}=1.03$ and $\varepsilon=0.021$.

\section{LNT PURGE CONTROL ALGORITHM}

To attain the best fuel economy, a lean burn engine must operate in the lean mode as long as possible, since that is where the fuel saving benefits are achieved. However, the fuel economy cannot be achieved at the expense of higher $\mathrm{NO}_{x}$ emissions. The trade-off between fuel economy and $\mathrm{NO}_{x}$ emissions is determined by the LNT purge strategy, in particular, by the following parameters in the strategy:

(1) The conditions under which the purge will be initiated;

(2) The conditions under which the purge will be terminated and lean operation resumed;

(3) The purge operation, i.e. the purge air-fuel ratio. 


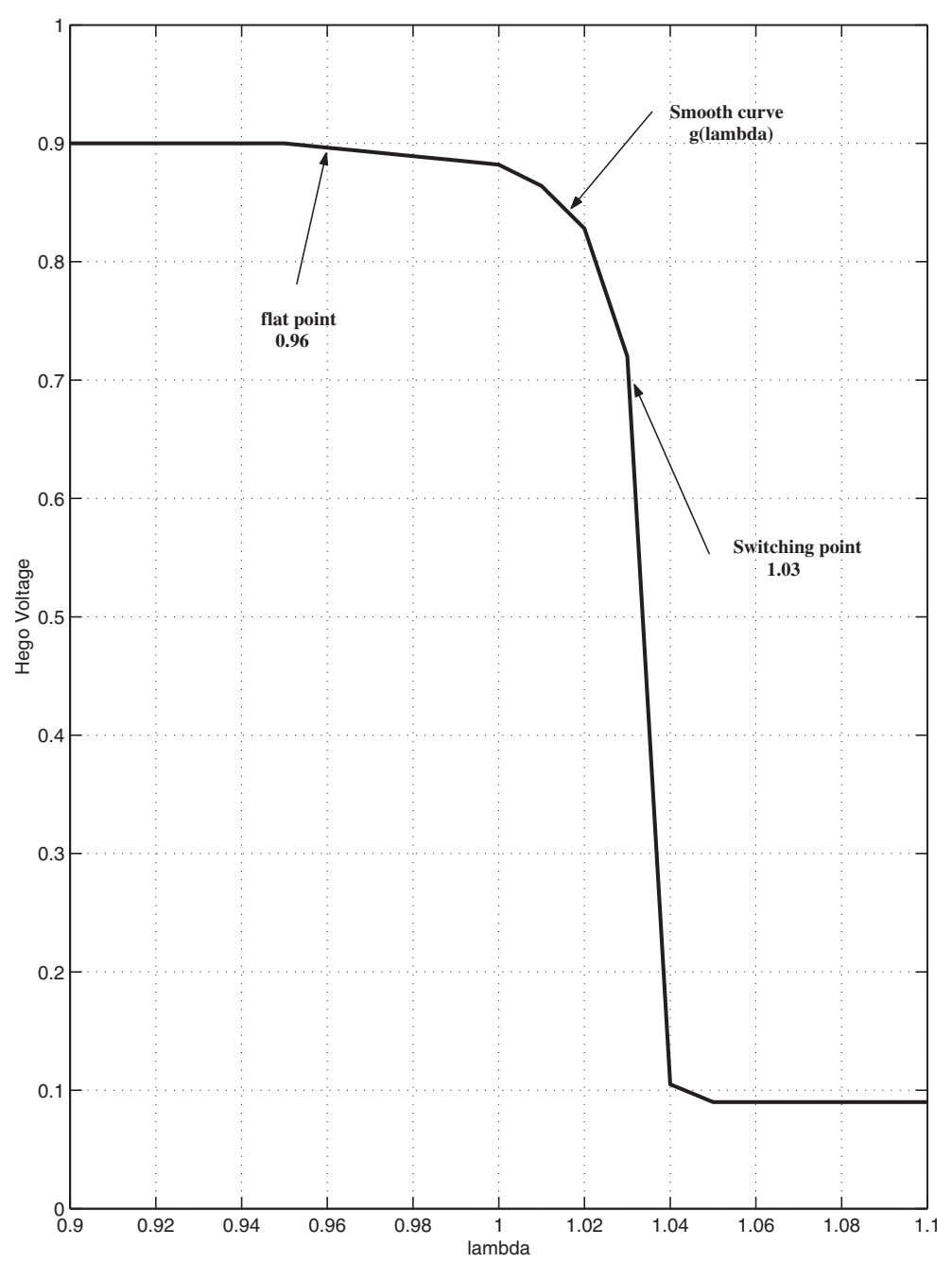

Figure 7. Relative AFR versus HEGO sensor emf.

Figure 8 shows the schematic diagram of a simple but effective LNT purge control strategy. It includes a model-based state estimator that provides an on-line estimation of the amount of stored $\mathrm{NO}_{x}$, and control logic that makes decisions of purge initiation and termination based on the estimated states and sensor information. After a period of lean operation when the stored $\mathrm{NO}_{x}$ exceeds a pre-calibrated threshold $\left(x \geqslant \bar{x}_{\mathrm{p}}\right)$, the lean burn or DISC engine will switch to purge operation where rich AFR will be commanded. The condition to terminate the purge and resume lean operation is determined by the HEGO signal and the purge model. When the HEGO signal switches from lean to rich $\left(v_{\text {tp }} \geqslant \bar{v}_{1}\right)$ or as the model projects, the stored $\mathrm{NO}_{x}$ falls below a pre-determined threshold $\left(x \leqslant x_{\text {res }}-\epsilon\right.$, where $x_{\text {res }}$ is the residual value of the stored $\mathrm{NO}_{x}$ in LNT at the time when HEGO switch takes place), whichever comes first, lean AFR will be commanded to return the engine operation to the lean mode. 


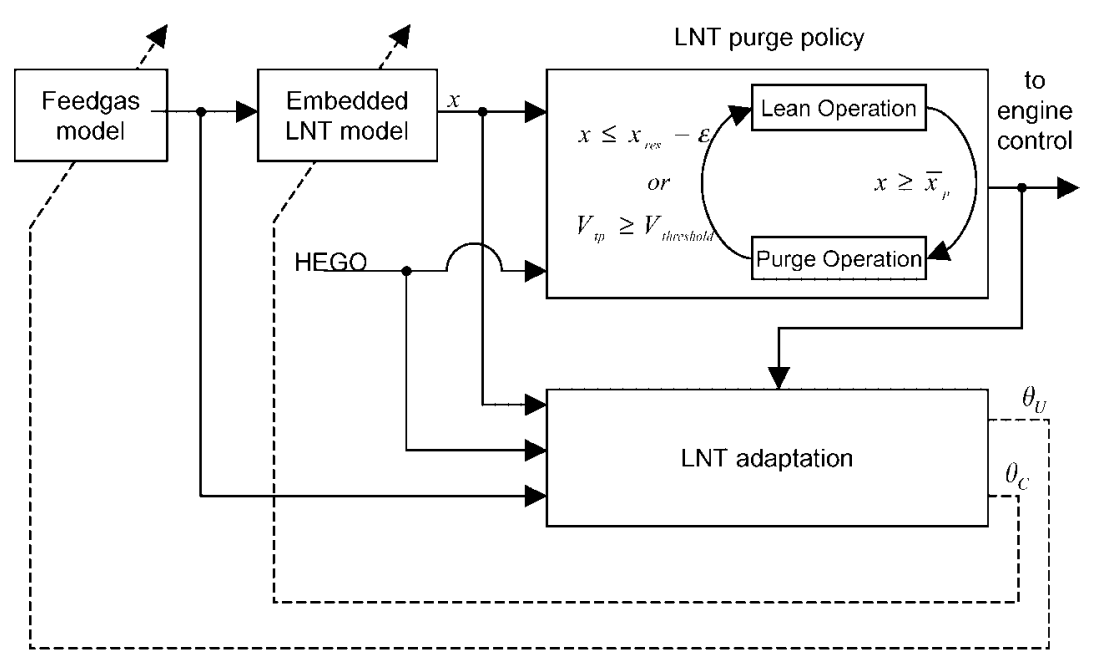

Figure 8. Schematic of LNT control strategy.

\section{Remark 3.1}

Without the on-board $\mathrm{NO}_{x}$ measurement, the HEGO voltage signal is normally used to interpret the end of purge. The break-through of reductant ( $\mathrm{HC}$ or $\mathrm{CO}$ ) at the end of the purge process will force the HEGO sensor to switch from lean to rich. One disadvantage of using the HEGO switch alone in this case is that, given the inevitable time delays in the system, this breakthrough will adversely affect $\mathrm{HC}$ and $\mathrm{CO}$ emissions. Conversely, relying solely on the model for LNT control could cause problems in the other direction due to uncertainties. That is, if the trap capacity is not precisely modelled, the purge may be terminated too early before the trap is completely purged of $\mathrm{NO}_{x}$, resulting in the loss of trap utility and storage efficiency in subsequent cycles. By combining the HEGO and LNT model information, and exploiting the on-board measurements to adjust the model parameters, we can minimize the $\mathrm{HC}$ and $\mathrm{CO}$ break-through in purge operation without compromising the $\mathrm{NO}_{x}$ performance during lean operation. This will be achieved through the adaptive scheme developed in the subsequent sections.

\section{Remark 3.2}

AFR is the most significant variable influencing system performance during the purge operation, since it determines the oxygen deficiency level (which affects the release rate and therefore the purge duration) and the amount of available reductant for converting the released $\mathrm{NO}_{x}$ (the $\mathrm{NO}_{x}$ conversion efficiency). With a near stoichiometric exhaust gas, the purge duration will be extended over a long period and the $\mathrm{NO}_{x}$ conversion efficiency will be very low. As the AFR becomes richer, the purge will end faster and $\mathrm{NO}_{x}$ conversion efficiency will increase. Further enriching AFR beyond a certain point, however, does little to improve the performance in terms of the purge duration and $\mathrm{NO}_{x}$ conversion efficiency. Figure 9 shows the sensitivity of the average fuel consumption and $\mathrm{NO}_{x}$ emissions over the storage/purge cycles for different AFR, and the best trade-off is shown to be around 12.5:1. For simplicity, we assume a fixed 


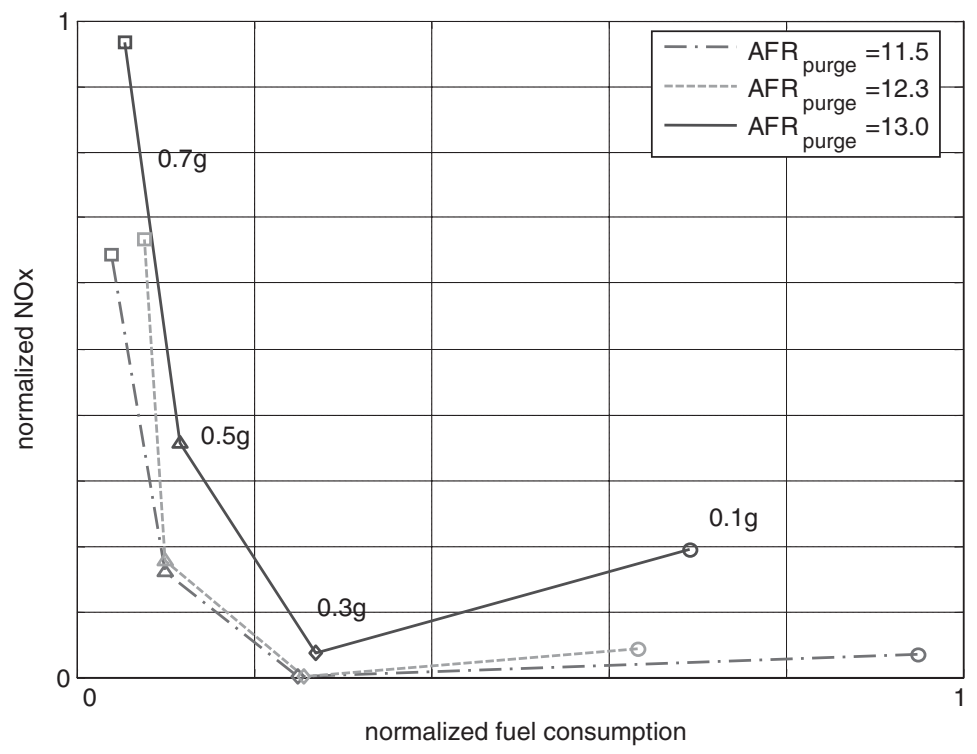

Figure 9. $\mathrm{NO}_{x}$ emission and fuel consumption trade-off.

AFR during the purge operation. The results, however, can be extended to more general strategies where more sophisticated AFR control is integrated.

\section{Remark 3.3}

Implementing the LNT control of Figure 8 requires knowledge of the internal state $x$, which, according to the LNT model (21), depends on the variables of in-coming $\mathrm{NO}_{x} \dot{m}_{\mathrm{NO}_{x} \text {, in }}$, temperature $T$, mass air flow rate $W_{\mathrm{a}}$, inlet AFR $\lambda_{\text {in }}$, and the stored oxygen $x_{\text {oxy }}$ which is another state of the model, along with other functions and parameters. Among these variables and functions, the following are considered to have significant impact on the performance and are most susceptible to uncertainties:

- Trap capacity $C_{\mathrm{LNT}}$. As mentioned earlier, sulphur poisoning is the primary source of uncertainty [6]. Other factors, such as thermal degradation due to ageing, also change the capacity slowly over time.

- In-coming $\mathrm{NO}_{x} \quad \dot{m}_{\mathrm{NO}_{x}, \text { in }}$. Without direct measurement, this quantity is subject to modelling uncertainties. The effects of environmental operating variables, such as humidity [12], are very difficult, if not impossible, to incorporate in the control-oriented model.

An adaptive control algorithm to address these two major parameter variations will be developed in the next section. Schemes to account for other uncertainties, such as the oxygen storage capacity and $\mathrm{NO}_{x}$ residual value at the end of the purge, will also be briefly discussed. 


\section{LNT PURGE CONTROL ADAPTATION}

In order to develop algorithms to adapt these changes, let us first explore the LNT model to define an appropriate parametric structure. Consider Figure 10, which depicts the trajectories of the downstream HEGO and the $\mathrm{NO}_{x}$ concentration in and out of the LNT during a lean/purge cycle. In the lean mode, from $t_{0}$ to $t_{1}$, the amount of stored $\mathrm{NO}_{x}$ can be calculated as

$$
W_{\mathrm{s}}=\int_{t_{0}}^{t_{1}} \eta_{\mathrm{s}} \dot{m}_{\mathrm{NO}_{x}, \text { in }} \mathrm{d} t
$$

Note that the stored $\mathrm{NO}_{x}\left(W_{\mathrm{s}}\right)$ is a function of storage efficiency $\eta_{\mathrm{s}}$ and the in-coming $\mathrm{NO}_{x}$ flow rate $\dot{m}_{\mathrm{NO}_{x} \text {,in }}$.

In the purge mode, from $t_{1}$ to $t_{2}$, the amount of released $\mathrm{NO}_{x}$ can be estimated by integrating the $\mathrm{NO}_{x}$ release rate over the purge interval

$$
W_{\mathrm{r}}=\int_{t_{1}}^{t_{2}} \dot{m}_{\mathrm{NO}_{x}, \mathrm{r}} \mathrm{d} t=\int_{t_{1}}^{t_{2}} C_{\mathrm{LNT}} k_{\mathrm{r}}(x) \mathrm{d} t
$$

Within the framework of the LNT model discussed in Section 2.2, the released $\mathrm{NO}_{x}\left(W_{\mathrm{r}}\right)$ happens to be a function of the $\mathrm{NO}_{x}$ storage capacity $C_{\mathrm{LNT}}$ and the normalized release rate $k_{\mathrm{r}}$. It should be noted that the released $\mathrm{NO}_{x}$ is different from the $\mathrm{NO}_{x}$ leaving the LNT during the purge phase. If controlled properly, a significant amount of the released $\mathrm{NO}_{x}$ will be converted to nitrogen and only a small portion of the released $\mathrm{NO}_{x}$ will leave the LNT unconverted.
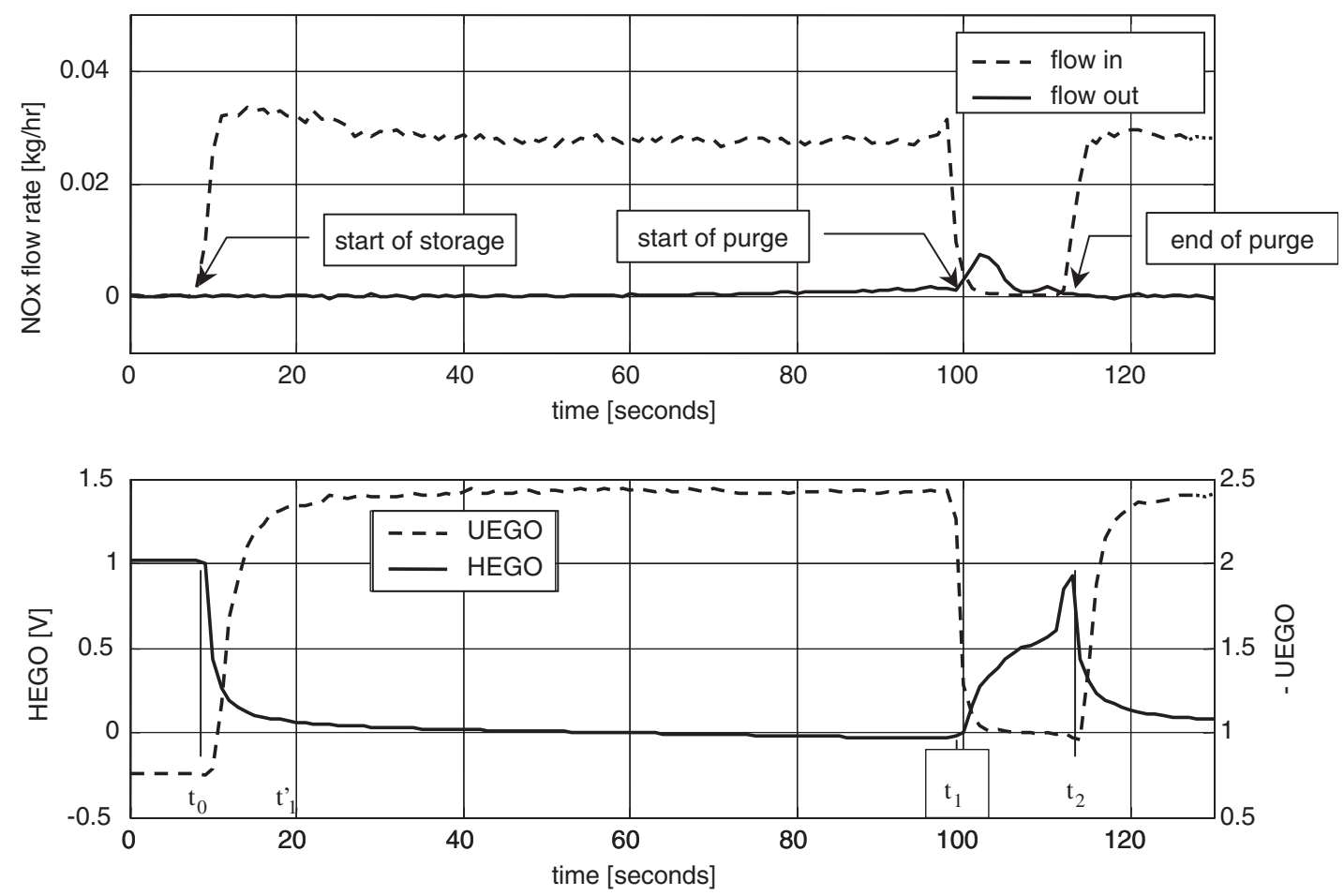

Figure 10. $\mathrm{NO}_{x}$ and HEGO response during a storage and purge cycle. 
From the conservation of mass, the amount of $\mathrm{NO}_{x}$ stored $\left(W_{\mathrm{s}}\right)$ and released $\left(W_{\mathrm{r}}\right)$ should be equal for a complete cycle which starts and ends with the same trap condition (the trap is considered either empty or with an undetectable residual $x_{\text {res }}$ at the end of purge), i.e.

$$
\int_{t_{1}}^{t_{2}} C_{\mathrm{LNT}} k_{\mathrm{r}}(x) \mathrm{d} t=\int_{t_{0}}^{t_{1}} \eta_{\mathrm{s}} \dot{m}_{\mathrm{NO}_{x}, \text { in }} \mathrm{d} t
$$

Equation (28) suggests a convenient parametric model for variations in capacity and in $\mathrm{NO}_{x}$ flow rate. Let $\theta_{\mathrm{c}}$ be an additive parameter for $C_{\mathrm{LNT}}$, i.e. $C_{\mathrm{LNT}}=C_{\mathrm{LNT}}^{0}+\theta_{\mathrm{c}}$, and $\theta_{\mathrm{u}}$ be a multiplicative parameter to $\dot{m}_{N o x}$, i.e. $\dot{m}_{\mathrm{NO}_{x}}=\theta_{\mathrm{u}} \dot{m}_{\mathrm{NO}_{x}}^{0}$, then Equation (28) leads to the parametric model:

$$
W_{\mathrm{r}}^{0}+\theta_{\mathrm{c}} T_{\mathrm{c}}=\theta_{\mathrm{u}} W_{\mathrm{s}}^{0}
$$

or

$$
W_{\mathrm{r}}^{0}=-\theta_{\mathrm{c}} T_{\mathrm{c}}+\theta_{\mathrm{u}} W_{\mathrm{s}}^{0}=\varphi^{\top} \theta
$$

where

$$
\begin{gathered}
W_{\mathrm{s}}^{0} \triangleq \int_{t_{0}}^{t_{1}} \eta_{\mathrm{s}} \dot{m}_{\mathrm{NO}_{x}, \text { in }}^{0} \mathrm{~d} t, \quad W_{\mathrm{r}}^{0} \triangleq \int_{t_{1}}^{t_{2}} C_{\mathrm{LNT}}^{0} k_{\mathrm{r}}(x) \mathrm{d} t, \quad T_{\mathrm{c}} \triangleq \int_{t_{1}}^{t_{2}} k_{\mathrm{r}}(x) \mathrm{d} t \\
\theta=\left[\theta_{\mathrm{c}}, \theta_{\mathrm{u}}\right]^{\top}, \quad \varphi=\left[-T_{\mathrm{c}}, W_{\mathrm{s}}{ }^{0}\right]^{\top}
\end{gathered}
$$

From the measured signals and the time stamps $\left[t_{0}, t_{1}, t_{2}\right]$ of a complete storage/purge cycle (see Figure 10), we can formulate the error signal $e$ which will serve as a basis for parameter adaptation:

$$
e=W_{\mathrm{r}}^{0}-\varphi^{\top} \theta
$$

\section{Remark 4.1}

The property that the normalized release rate $k_{\mathrm{r}}$, defined in (18), is independent of the trap capacity for a given LNT is critical in deriving the linear parametric model. As discussed in Section 3 (Remark 3.1), this property is validated by experimental data shown in Figure 4.

\section{Remark 4.2}

It should also be noted that using additive for capacity uncertainty and multiplicative for incoming $\mathrm{NO}_{x}$ in the parametrization is motivated by the physical properties of the system. On the one hand, the capacity $C_{\mathrm{LNT}}$, as a single-valued quantity, changes slowly with respect to time due to system ageing and sulphur poisoning. On the other hand, the in-coming $\mathrm{NO}_{x}$ changes dynamically as the operating condition (such as speed and load) changes. The effects of the slow changing factors that the adaptation attempts to address, such as humidity and fuel quality change, are, however, similar across different speed and load ranges.

When the combined model-based and HEGO feedback LNT control strategy discussed in Section 3 is implemented, there are two possible scenarios: (a) The HEGO switches to high voltage at $t_{2}$ and the model indicates the purge has not been completed. In this case, $\left[t_{0}, t_{1}, t_{2}\right]$ can be determined and the error $e$ can be evaluated to provide both qualitative and quantitative information and be used for parameter update. (b) The model predicts the end of purge before 
the HEGO sensor switches. In this case, the controller of Figure 8 will terminate the purge without waiting for a HEGO switch and one cannot determine the actual value of $t_{2}$ when the trap is truly empty. However, it can be concluded that $t_{2}^{\prime}<t_{2}$ where $t_{2}^{\prime}$ is the calculated purge end time according to the model. The model is either over-estimating the release rate or underestimating the stored $\mathrm{NO}_{x}$. Instead of calculating $e$ from Equation (31), we only use the sign information about the error $e>0$ for parameter adaptation.

For parameter update, a number of different adaptive control schemes can be employed, thanks to the linear parametric model (29). For on-board application, the projection algorithm [13] has the advantage of being simple and requires less computational resource:

$$
\begin{gathered}
\theta_{k+1}=\theta_{k}-\frac{\gamma \varphi_{k} e_{k}}{\alpha+\varphi_{k}^{\mathrm{T}} \varphi_{k}} \text { when } v_{\mathrm{tp}}=\text { high at } t_{2} \text { (i.e. HEGO switches first) } \\
\theta_{k+1}=\theta_{k}-\frac{\gamma \varphi_{k}}{\alpha+\varphi_{k}^{\mathrm{T}} \varphi_{k}} \text { when } v_{\mathrm{tp}}=\text { low at } t_{2} \text { (i.e. model switches first) }
\end{gathered}
$$

where $\alpha \geqslant 0$ and $0<\gamma<2$. The parameter convergence may be improved by using other more complex estimation algorithms, such as the recursive least-squares algorithm, which will not be further detailed here.

For parameter convergence, a persistent excitation (PE) condition is derived in Reference [5] with varying threshold for purge initiation. More specifically, for a fixed or varying $\dot{m}_{\mathrm{NO}_{x} \text {, in }}$, by changing $t_{1}, \mathrm{PE}$ and parameter identifiability are guaranteed for the non-linear parametric model addressed in Reference [5]. For the new parametric model (29) used in this development, however, the PE condition manifests itself in a different form. In fact, it can be shown that the same condition that guaranteed persistent excitation for the adaptive scheme in Reference [5] does not provide the PE property for the new parametric model (29). As shown in Figure 11, for fixed $\dot{m}_{\mathrm{NO}_{x} \text {,in }}$, there is a strong linear correlation between $T_{\mathrm{c}}$ and $W_{\mathrm{s}}{ }^{0}$ no matter what the value of $t_{1}$ is. It can be shown for this two-parameter adaptation scheme, however, that by varying $\dot{m}_{\mathrm{NO}_{x} \text {,in }}$, PE will be provided for the parametric model (29) that will lead to parameter convergence for most standard adaptation algorithms.

Using the HEGO sensor measurement and its characteristics, we can also extract information regarding the catalyst oxygen storage capacity $C_{\text {oxy }}$ and the residual $\mathrm{NO}_{x}$ in the trap at the end of purge $x_{\text {res }}$, and use the information for controller adaptation or on-board diagnosis. The algorithms involved are briefly discussed as follows:

\section{Remark 4.3}

The oxygen storage capacity for the trap can be estimated using HEGO switch information. During the lean operation, when the HEGO sensor switches from high to low voltage at $t_{1}^{\prime}$ (as indicated on Figure 10), we have $\lambda_{\mathrm{tp}}\left(t_{1}^{\prime}\right)=1$. From (33), this corresponds to the point when $\rho_{\mathrm{L}}\left(x_{\mathrm{oxy}}\right)=1 / \alpha_{\mathrm{L}}$, or $x_{\mathrm{oxy}}\left(t_{1}^{\prime}\right)=\rho_{\mathrm{L}}^{-1}\left(1 / \alpha_{\mathrm{L}}\right)$. On the other hand, from the oxygen storage ((23) and (24)) and the HEGO model (25), the stored oxygen in the catalyst can be calculated as

$$
m_{\text {oxy }}(t)=\int_{0}^{t}\left[\frac{\lambda_{\text {in }}-g^{-1}\left(v_{\text {tp }}(t)\right)}{\lambda_{\text {in }}(t)} 0.21 W_{\mathrm{a}}\right] \mathrm{d} t
$$

The oxygen storage capacity can be estimated using the relation:

$$
C_{\text {oxy }}=m_{\text {oxy }}\left(t_{1}^{\prime}\right) / x_{\text {oxy }}\left(t_{1}^{\prime}\right)
$$




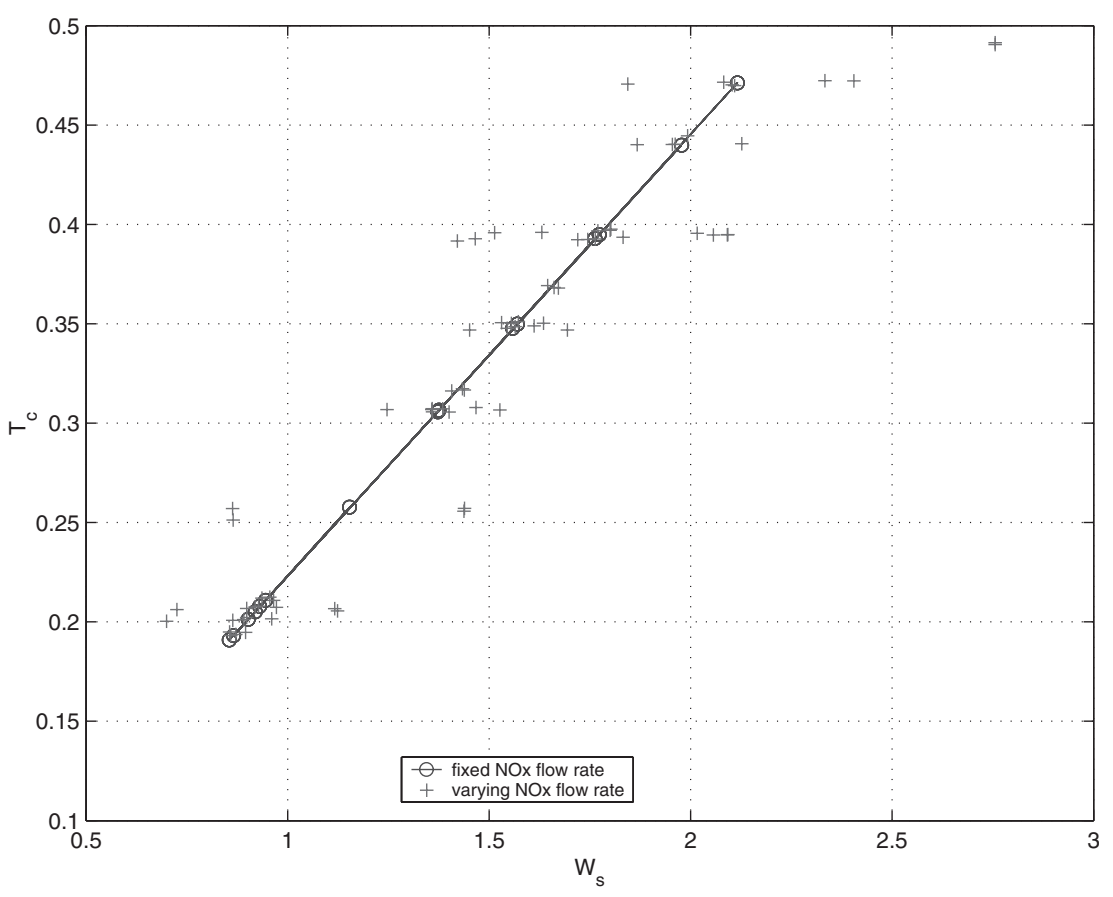

Figure 11. $T_{\mathrm{c}}$ versus $W_{\mathrm{s}}^{\mathrm{o}}$ for varying $t_{1}$ with and without input excitation.

To improve robustness, it is better to have this estimation carried out over several cycles using a standard averaging or weighted least-squares algorithm. It should also be pointed out that while the information of $C_{\text {oxy }}$ is not used explicitly in the LNT control algorithm delineated in Section 3 , it is nevertheless important to continuously monitor the catalyst status (that is, the capacity) for the purpose of on-board diagnostics.

\section{Remark 4.4}

In most applications, the residual $\mathrm{NO}_{x}$ in the LNT is assumed to be equal to zero when the downstream HEGO switches from low to high voltage. Depending on the catalyst and HEGO characteristics, however, there are cases where there is a non-zero residual in the trap at the time of HEGO switch, and this residual can be estimated using a more sophisticated HEGO sensor model. This model, as is described in Reference [14], uses the mass balance of the oxidants and reductant at the switching point to determine the $\mathrm{NO}_{x}$ release rate and the corresponding LNT loading. It requires the knowledge of the in-coming flow rates for the reductant (i.e. $\mathrm{CO}$ and $\mathrm{HC}$ ), which can in turn be inferred from the AFR and engine operating condition.

\section{SIMULATION RESULTS}

The proposed adaptation algorithm is tested on a simulation model to evaluate its effectiveness in the following different scenarios: Case A: over-estimated trap capacity and under-estimated 

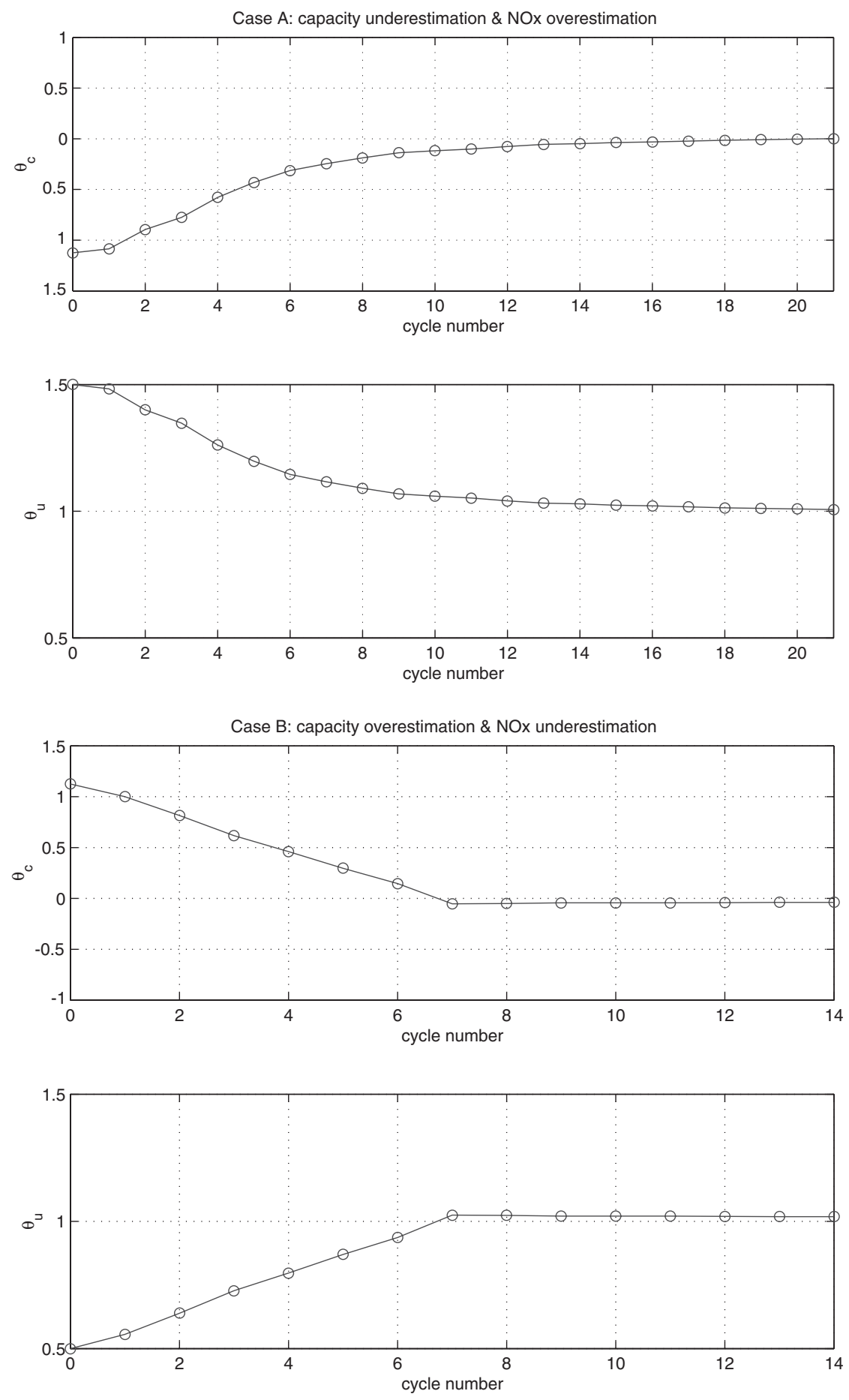

Figure 12. Adaptation results with various scenarios. 

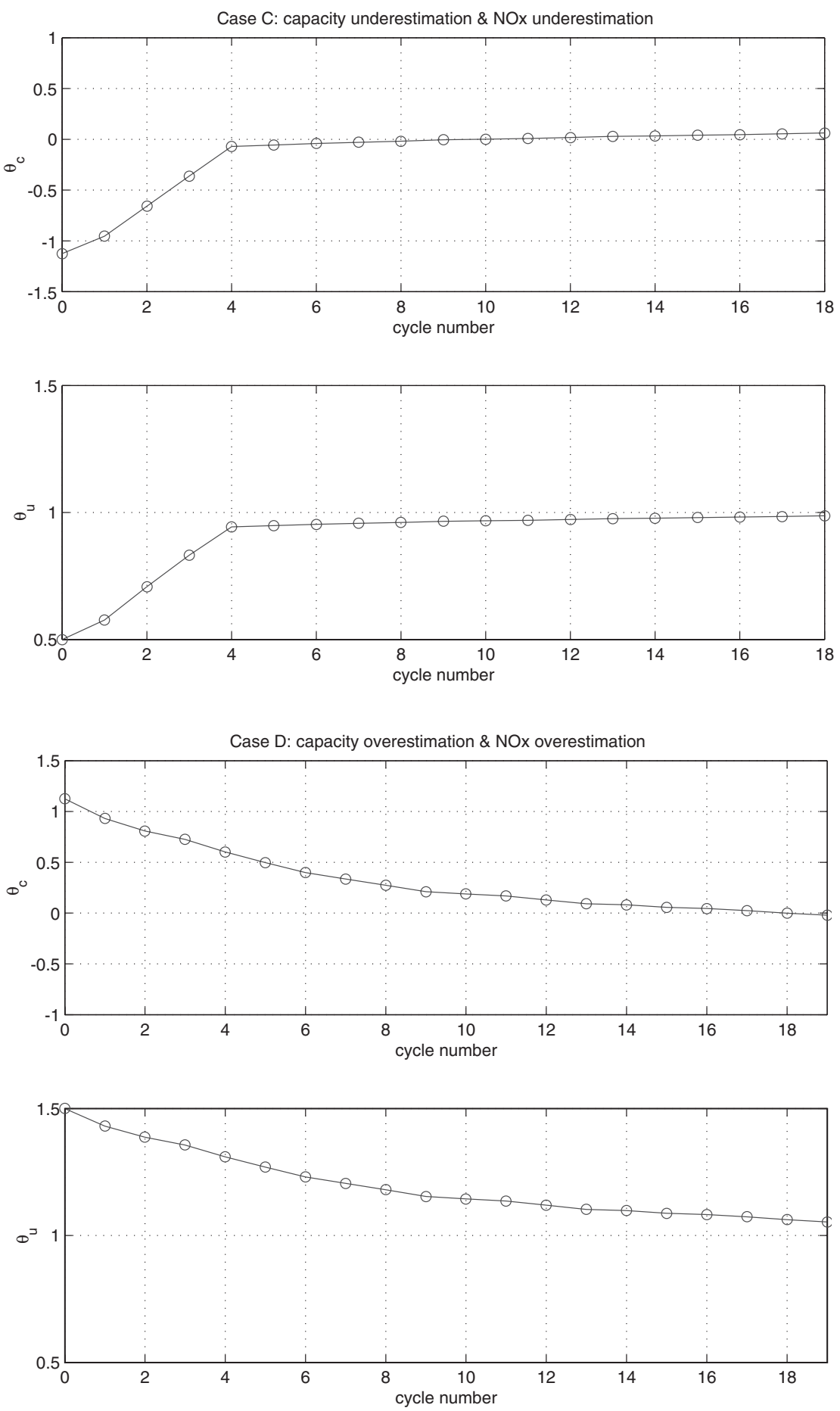

Figure 12. Continued. 
Table I. Adaptation error.

\begin{tabular}{lllll}
\hline & Case A & Case B & Case C & Case D \\
\hline Capacity error & 0.04 & 0.86 & 1.38 & 0.46 \\
$\mathrm{NO}_{x}$ flow rate error & 0.68 & 1.87 & 1.31 & 5.34 \\
\hline
\end{tabular}

Note: Error in absolute \%, initial error in capacity $=25 \%$, initial error in $\mathrm{NO}_{x}=50 \%$.

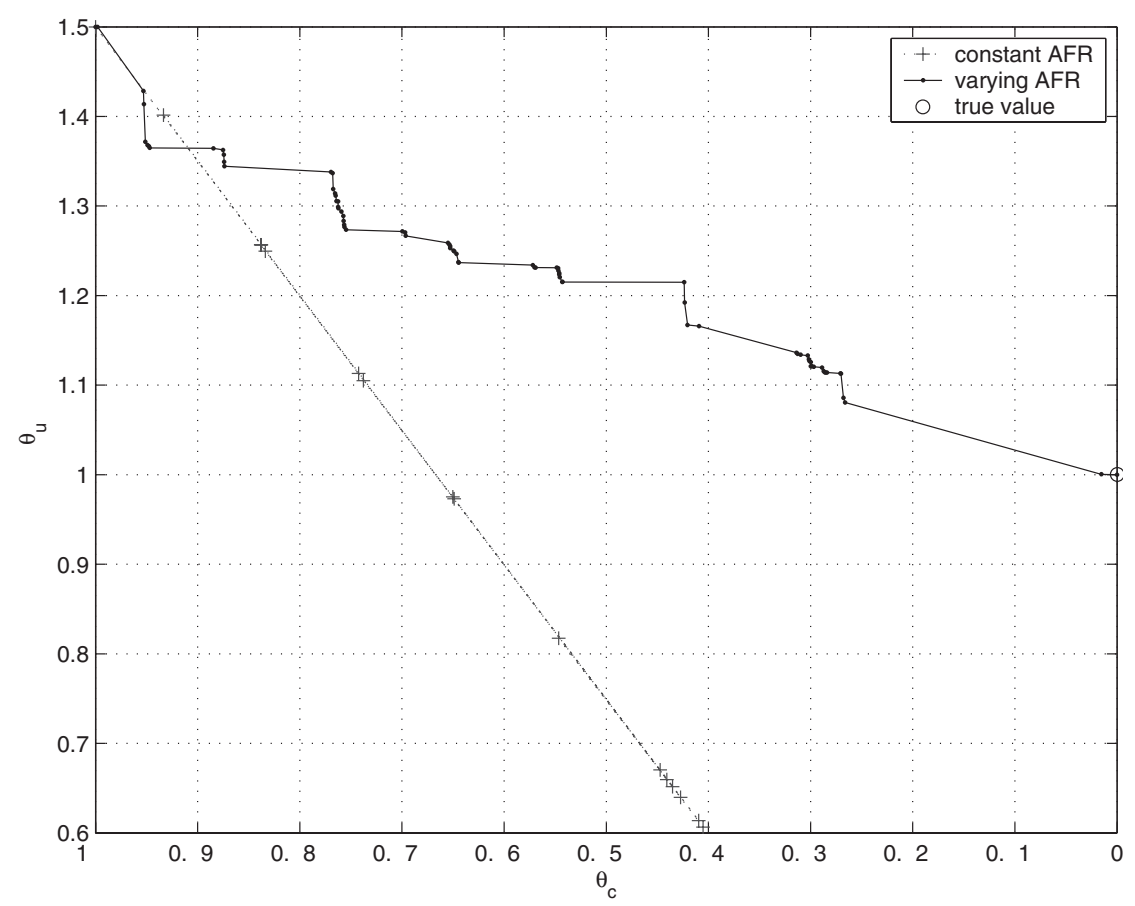

Figure 13. Parameter convergence with persistent excitation by various AFRs.

$\mathrm{NO}_{x}$; Case B: capacity and $\mathrm{NO}_{x}$ both over-estimated; Case C: under-estimated capacity and over-estimated $\mathrm{NO}_{x}$; Case D: capacity and $\mathrm{NO}_{x}$ both under-estimated. The results are shown in Figure 12 and summarized in Table I. In all those cases, the parameters converge to the desired value, and the model predicted purge ending time approaches the HEGO switch time.

Figure 13 shows the performance of the adaptation scheme with or without the PE condition. When the engine is running at a fixed speed and load condition with constant control inputs, the in-coming $\mathrm{NO}_{x}$ to the LNT is kept constant and therefore the PE condition is not satisfied. This leads to the result shown in Figure 13 where the parameter does not converge to the desired value. On the other hand, at the same speed and load operating point, we change the AFR and therefore the in-coming $\mathrm{NO}_{x}$ flow rate to the trap during the lean operation. As shown in Figure 13, this provides sufficient excitation for parameter convergence, and consequently, the parameters converge to the true parameter of $\theta_{\mathrm{u}}=1$ and $\theta_{\mathrm{c}}=0$. 


\section{CONCLUSIONS}

Motivated by real-world application constraints, we investigated the problem of model-based LNT control and on-board adaptation using the existing low-cost HEGO sensor. By exploring the physical characteristics of the system and sensor, we identified a feasible LNT model structure that leads to a control-oriented representation for which the uncertain parameters appear linearly. This model facilitates the efficient on-line adaptation for the trap capacity and in-coming $\mathrm{NO}_{x}$ flow rate without imposing restrictive computational requirements for on-board implementation. Simulation results show that, when integrated with the model-based LNT control, the adaptation improves the aftertreatment control robustness by maintaining the desired trade-offs between fuel economy and emissions.

The aftertreatment technology is fast changing with many technical innovations on the horizon. Opportunities are abundant for control engineers to apply advanced techniques to address performance, reliability and diagnostics issues. Following the line of research delineated in the paper, we plan to continue the investigation of improving system performance with limited sensor information. Coordinated control and diagnostics design represent another challenge where on-line system identification and adaptation can play an important role.

\section{ACKNOWLEDGEMENTS}

The authors would like to express their appreciations to Jeff Koncsol and Bill Duchene for their assistance in setting up the experimental facility and acquiring data. The authors have also benefited a great deal from their stimulating discussions with Julia Buckland, Jeff Cook, and Ilya Kolmanovsky, all from Ford Motor Company.

\section{REFERENCES}

1. Ketfi-Cherif A, Wissel D, Beurthey S, Sprine M. Modeling and control of a $\mathrm{NO}_{x}$ trap catalyst. SAE 2000-01-1199, 2000 .

2. Hepburn JS, Thanasiu E, Dobson DA, Watkins WL. Experimental and modeling investigations of $\mathrm{NO}_{x}$ trap performance. SAE 962051, 1996.

3. Kojima S, Baba N, Matsunaga S, Senda K, Katoh K, Itoh T. Modeling and numerical analysis of $\mathrm{NO}_{x}$ storagereduction catalysts - on the two effects of rich-spike duration. SAE 2001-01-1297, 2001.

4. Wang Y, Raman S, Grizzle J. Dynamic modeling of a lean $\mathrm{NO}_{x}$ trap for lean burn engine control. Proceedings of the American Control Conference, San Diego, USA, 1999.

5. Wang LY, Kolmanovsky I, Sun J. On-line identification and adaptation of LNT models for improved emission control in lean burn automotive engines. Proceedings of the American Control Conference, Chicago, USA, 2000.

6. Li J, Theis JR, Chun W, Goralski CT, Kudla RJ, Watkins WL, Hurley RH. Sulfur poisoning and desulfation of the lean $\mathrm{NO}_{x}$ trap. SAE 2001-01-2503, 2001.

7. Kim YW, Sun J, Kolmanovsky I, Koncsol J. A phenomenological control oriented lean $\mathrm{NO}_{x}$ trap model. SAE 200303FL-119, 2003.

8. Brandt E, Wang Y, Grizzle J. Dynamic modeling of a three-way catalyst for SI engine exhaust emission control. IEEE Transactions on Control Systems Technology 2000; 8(5):767-776.

9. Brailsford AD, Yussouff M, Logothetis EM. Theory of gas sensors. Sensors and Actuators B 1993; 13:135-138.

10. Brailsford AD, Yussouff M, Logothetis EM, Wang T, Soltis RE. Experimental and theoretical study of the response of $\mathrm{ZrO}_{2}$ oxygen sensors to simple one-reducing-gas mixtures. Sensors and Actuators B 1997; 42:15-26.

11. Wang T, Soltis RE, Logothetis EM, Cook JA, Hamburg DR. Static characteristics of $\mathrm{ZrO}_{2}$ exhaust gas oxygen sensors. SAE Paper 930352, 1993.

12. Robinson JA, Humidity effects on engine nitric oxide emissions at steady-state conditions. SAE 700467, March 1970.

13. Ioannou PA, Sun J. Robust Adaptive Control. Prentice-Hall: Englewood Cliffs, NJ, 1996.

14. Wang LY, Kim YW, Sun J. Prediction of oxygen storage capacity and stored $\mathrm{NO}_{x}$ using HEGO sensor model for improved LNT control strategies. International Mechanical Engineering Congress and Exposition (ASME), New Orleans, USA, 2002. 